\title{
Observational evaluation of preoperative,
} intraoperative, and postoperative characteristics in 1 I 7 Brazilian women without uterine prolapse undergoing vaginal hysterectomy

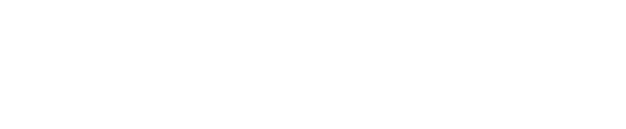

\author{
Claudio Sergio Batista' \\ Takasi Osako² \\ Eliana Mara Clemente ${ }^{2}$ \\ Fernanda Carvalhido \\ Antonio Batista ${ }^{3}$ \\ Maurício Takeshi Janiques \\ Osako $^{4}$ \\ 'Department of Gynecology and \\ Obstetrics of Faculty of Medicine \\ of Petropolis, Petropolis, Rio de \\ Janeiro, Brazil; ${ }^{2}$ Gynecology and \\ Obstetrics, Casa Providencia Hospital, \\ Petropolis, Rio de Janeiro, Brazil; \\ ${ }^{3}$ School of Medicine of Technical \\ Educational Foundation Souza \\ Marques, Rio de Janeiro, Brazil; \\ ${ }^{4}$ School of Medicine of University \\ Gama Filho, Rio de Janeiro, Brazil
}

Background: Despite the introduction of minimally invasive approaches for various benign uterine problems, hysterectomy is often still performed abdominally, but the vaginal route should be used whenever possible. The aim of this study was to identify the preoperative, intraoperative, and postoperative characteristics of women undergoing vaginal hysterectomy in the absence of uterine prolapse.

Methods: A prospective, descriptive, quantitative, noncomparative study was conducted in 117 women between August 2009 and February 2011 in Petropolis, Rio de Janeiro, Brazil. The women included had a uterine indication for hysterectomy, their surgeries were performed by the same team, and they were followed up for 12 months. An adapted Pelvic Organ Prolapse Quantification system was used to check for uterine prolapse.

Results: The age range of the women was 33-59 years, uterine volume was $300-900 \mathrm{~mL}$, and $73.50 \%$ has undergone prior cesarean section. The main indication for hysterectomy was uterine myoma (64.95\%), with a surgery time of 30-60 minutes in $55(59.82 \%)$ and $19(15.98 \%)$ cases, respectively. Uterine volume reduction was performed in $41(35.05 \%)$ cases, salpingectomy was the most common associated surgery $(81.19 \%)$, and anesthesia was subdural $(68.37 \%)$. Common intraoperative complications included bladder lesions $(8.54 \%)$, with conversion to the abdominal route being necessary in one case (1.28\%), and the most common postoperative complication being vaginal cupola granuloma (32.47\%). There was a statistically significant relationship between surgery time and uterine volume $\left(\chi^{2}=17.367 ; P=0.002\right)$.

Conclusion: This study suggests that vaginal hysterectomy is a safe surgical procedure in view of its good performance and low complication rate.

Keywords: vaginal hysterectomy, surgical procedure, enlarged uterus, myoma, women

\section{Introduction}

Vaginal hysterectomy involves removal of the uterus via the vaginal route, with no abdominal incision, and should be performed whenever possible in preference to abdominal hysterectomy. ${ }^{1}$ However, despite vaginal hysterectomy being recommended, and numerous studies supporting its benefits and safety, many hysterectomies are still performed abdominally, ${ }^{3,4}$ with several reasons, including lack of pelvic relaxation, a history of prior pelvic surgery, nulliparity, and large uterine size, being used as justification. US data show that the abdominal route is still used in about $66 \%$ of cases, while the vaginal route is used in $22 \%$ and laparoscopic hysterectomy in about $12 \%$ of cases. $^{5}$
Correspondence: Claudio Sergio Batista Rua do Imperdor, 288/908 Centro, Petropolis, Rio de Janeiro,

Brazil CEP 25620-000

Tel +55 2422313630

Fax +55 24223 I 3630

Email csergiobatista@gmail.com.br 
A number of factors that can influence the choice of route of hysterectomy for benign diseases and presented reasons include uterine size and accessibility, uterine and vaginal shape, extrauterine disease, need for concomitant procedures, training and experience of the surgical team, hospital support with adequate material and available emergency sector, and patient preference. ${ }^{6}$ A narrow pubic arch ( $<90$ degrees), narrow vagina, uterine immobility, nulliparity, prior cesarean section, and a large uterine volume are considered by some authors to be contraindications to vaginal hysterectomy. However, other authors have shown that nulligravida and those with a history of cesarean section can have sufficient vaginal caliber to allow use of the vaginal route for hysterectomy. ${ }^{7}$

Newer evidence indicates that the vaginal route is indeed safe for hysterectomy, even for larger uterine volumes, ${ }^{8-10}$ and the literature has demonstrated that, when feasible, vaginal hysterectomy is more cost-effective for uterine removal. ${ }^{1}$ Even when the uterine volume is large, vaginal hysterectomy can be carried using uterine volume reduction techniques such as myomectomy, uterine morcellation, uterine hemisection, intramyometrial reduction (Lash's technique), uterine wall wedge resection, and amputation of the uterine cervix, with the aim of obtaining access to the base of the uterus. ${ }^{11}$ In a 2009 Cochrane review, Niebore et al reviewed 34 studies comparing abdominal, vaginal, and laparoscopic hysterectomy in 4495 patients, and found the best results for the vaginal route. ${ }^{1}$ Doucette et al supported this finding, stating that it was their experience, ie, when the vagina is ample enough to allow access of uterosacral and cardinal ligaments, uterine mobility increases and allows accomplishment of vaginal hysterectomy even in those cases where uterine descending with initial traction is minimum. ${ }^{12}$

We have performed vaginal hysterectomies for a long time, and our experience is that the vaginal route is a safe, rapid, and cost-effective way to perform this surgery. The purpose of this study was to evaluate preoperative, intraoperative, and postoperative parameters in women without uterine prolapse undergoing vaginal hysterectomy.

\section{Materials and methods}

We carried out this prospective, descriptive, quantitative, noncomparative study in 117 women between August 2009 and February 2011 in Petropolis, Rio de Janeiro, Brazil. All the women had presented with an indication for hysterectomy, including myoma, endometrial hyperplasia, or abnormal uterine bleeding, and none had uterine prolapse. The subjects were assessed for vaginal hysterectomy after signing an informed consent form. All operations were performed by the same surgical team and the patients were followed up for 12 months, with assessments at 1, 2, 3, 6, 9, and 12 months following surgery to check for early or late complications and their evolution.

We used the Pelvic Organ Prolapse Quantification system criteria standardized by the International Continence Society ${ }^{13}$ to exclude uterine prolapse. This system uses the hymenal caruncle as the fixed point of reference, with six defined points, ie, Aa, Ba, C, D, Ap, and Bp, and three additional landmarks, ie, the genital hiatus, total vaginal length, and perineal body. Each point is measured in $\mathrm{cm}$ above or proximal to the hymen (negative number) or $\mathrm{cm}$ below or distal to the hymen (positive number), with the plane of the hymen being defined as zero. The hymen was selected rather the introitus as the reference point because it is more precisely identified. ${ }^{14}$ There are three reference points anteriorly (Aa, $\mathrm{Ba}$, and $\mathrm{C}$ ) and three posteriorly (Ap, Bp, and D). Points $\mathrm{Aa}$ and Ap are $3 \mathrm{~cm}$ proximal to or above the hymenal ring anteriorly and posteriorly, respectively. Points $\mathrm{Ba}$ and $\mathrm{Bp}$ are defined as the lowest points of the prolapse between Aa anteriorly or Ap posteriorly and the vaginal apex. Anteriorly, the apex is point $C$ (cervix), and posteriorly is point $D$ (pouch of Douglas). After hysterectomy, point $\mathrm{C}$ is the vaginal cuff and point $\mathrm{D}$ is omitted. Three other measurements are taken, ie, the vaginal length at rest, the genital hiatus from the middle of the urethral meatus to the posterior hymenal ring, and the perineal body from the posterior aspect of the genital hiatus to the mid anal opening ${ }^{15}$ (see Figure 1).

Inclusion criteria were any medical indication for hysterectomy, including myoma, endometrial hyperplasia, uterine

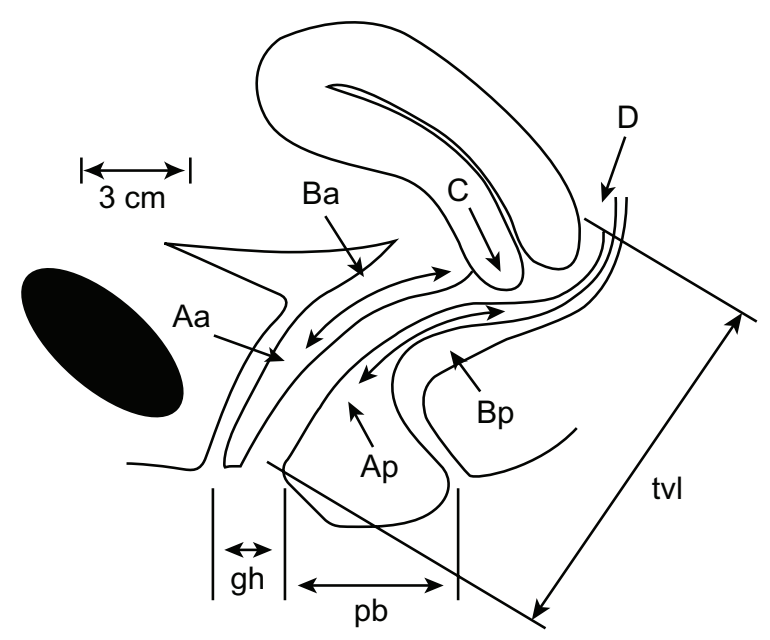

Figure I Points and landmarks for Pelvic Organ Prolapse Quantification system examination.

Abbreviations: $A a$, point $A$ anterior; $A p$, point $A$ posterior; $B a$, point $B$ anterior; $B$, point $B$ posterior; $C$, cervix or vaginal cuff; $D$, posterior fornix (if cervix is present); gh, genital hiatus; pb, perineal body; TVL, total vaginal length. 
polyps, and cervical intraepithelial neoplasia. Exclusion criteria were any grade of uterine prolapse, uterine or cervical cancer, and confirmed or suspected primary adnexal pathology.

Preoperative variables recorded were patient age, surgical indication, uterine volume, parity, route of delivery, and prior (including gynecological) surgery. Intraoperative variables recorded were duration of surgery, type of anesthesia, need for conversion to abdominal surgery, bladder lesions, and hemorrhage. Postoperative variables recorded were duration of hospitalization, hemorrhage, infection at the surgical site, urinary tract infection, and development of vaginal cupola hematoma or granuloma.

Salpingectomy was indicated and performed in all patients, and oophorectomy was performed in those who were postmenopausal. Complementary surgeries, such as posterior culdoplasty and sacrospinal ligamentopexy, were carried out as indicated.

The data were analyzed using SPSS software (SPSS Inc, Chicago, IL), with frequency, median, and standard deviation used for quantitative variables. Chi-square testing was used to identify any statistically significant relationships between surgery time and uterine volume, associated surgery, and previous surgery. Findings were considered to be significant at $P=0.05$.

\section{Results}

\section{Preoperative characteristics}

The mean age was 46 (range 33-59) years. Uterine volume was divided to three bands, ie, $\leq 300 \mathrm{~mL}$ (64.95\%), 301$600 \mathrm{~mL}(21.36 \%)$, and 601-900 mL. Parity was similarly classified as one $(9.40 \%)$, two $(52.99 \%)$, and three or more fetuses $(37.60 \%)$. Delivery had been by the vaginal route in $26.49 \%$ and by cesarean section in $73.50 \%$. Indications for hysterectomy were uterine myoma $(64.95 \%)$, abnormal uterine bleeding (23.93\%), endometrial hyperplasia (5.98\%), pelvic pain $(3.41 \%)$, and endometrial cancer $(1.70 \%)$. Associated surgical conditions were ovarian cyst, urinary incontinence, rectocele, cystocele, and hydrosalpinx. Prior related surgeries included fallopian tube ligation (44.44\%), oophoroplasty/oophorectomy $(5.12 \%)$, myomectomy (3.41\%), and appendectomy (5.12\%). More than one previous surgery was recorded for $29.91 \%$ of cases. General preoperative characteristics for the study population are summarized in Table 1.

\section{Intraoperative characteristics}

Surgery time was up to 30 minutes in 55 (59.82\%) cases, 31-60 minutes in $43(24.78 \%)$ cases, and more than
Table I General preoperative characteristics in the study population $(n=117)$

\begin{tabular}{lll}
\hline Variable & Value & Median \\
\hline Age & $45.21 \pm 5.57$ & 46 \\
Uterine volume & $327.33 \pm 216.0$ I & 240 \\
Parity & $2.4 \pm 0.87$ & 2 \\
Route of delivery & & \\
$\quad$ Vaginal route & $31(26.9 \%)$ & \\
$\quad$ Cesarean section & $86(73.50 \%)$ & \\
Surgical indication & & \\
$\quad$ Uterine myoma & $76(64.95 \%)$ & \\
Abnormal uterine bleeding & $28(23.93 \%)$ & \\
Endometrial hyperplasia & $7(5.98 \%)$ & \\
$\quad$ Pelvic pain & $4(3.41 \%)$ & \\
Associated surgical conditons & & \\
$\quad$ Ovarian cyst & $31(26.49 \%)$ & \\
Urinary incontinence & $18(15.38 \%)$ & \\
Rectocele & $43(36.75 \%)$ & \\
Prior surgery & & \\
$\quad$ Tubal ligation & $52(44.44 \%)$ & \\
Oophoroplasty/oophorectomy & $6(5.12 \%)$ & \\
Myomectomy & $4(3.41 \%)$ & \\
Appendectomy & $6(5.12 \%)$ & \\
More than one surgery & $35(29.91 \%)$ & \\
\hline
\end{tabular}

60 minutes in 19 (15.98\%) cases. Uterine volume reduction techniques were not necessary in 76 (64.95\%) cases, but were needed in 41 (35.04\%) to complete the hysterectomy. The most commonly associated surgery was salpingectomy $(81.19 \%)$, but several patients had gynecological surgery

Table 2 General intra-operative characteristics in the studied population $(n=117)$

\begin{tabular}{lll}
\hline Variable & Value & Median \\
\hline Surgery time & $43.15 \pm 18.06$ & 38.00 \\
Surgical technique & & \\
Without uterine reduction & $76(64.95 \%)$ & \\
With uterine reduction & $41(35.04 \%)$ \\
Morcellation & $3(7.31 \%)$ & \\
Uterine cervix amputation & $3(7.31 \%)$ \\
Uterine wall wedge resection & $2(4.87 \%)$ \\
Myomectomy & $7(17.07 \%)$ \\
Uterine bipartition & $4(9.75 \%)$ \\
Myometrium section (Lash's technique) & $22(53.65 \%)$ \\
Associate surgery & \\
Salpingectomy* & $95(81.19 \%)$ \\
Ovarian surgery & $31(26.49 \%)$ \\
Transobturator sling & $18(15.38 \%)$ \\
Posterior colpoplasty & $43(36.75 \%)$ \\
Anesthesia & & \\
Spinal anesthesia & $80(68.37 \%)$ \\
General anesthesia & $10(8.54 \%)$ \\
Spinal + general anesthesia & $27(23.07 \%)$ \\
Conversion to abdominal route & $1(1.28 \%)$ \\
Bladder lesion & $10(8.54 \%)$ \\
Hemorrhage & $1(1.28 \%)$ \\
\hline
\end{tabular}

Note: *Salpingectomy was routinely performed jointly to other complementary surgical procedures. 
Table 3 General postoperative characteristics in the studied population $(n=117)$

\begin{tabular}{lll}
\hline Variable & Value & Median \\
\hline Hospitalization time & $28.31( \pm 9.25)$ & 24 \\
Urinary infection & $15(12.82 \%)$ & \\
Vaginal cupola hematoma & $3(2.56 \%)$ & \\
Vaginal cupola granuloma & $38(32.47 \%)$ & \\
\hline
\end{tabular}

additional to salpingectomy, including ovarian surgery in $31(26.49 \%)$ cases, a transobturator sling procedure in $18(15.38 \%)$ cases, and posterior culdoplasty in $43(36.75 \%)$ cases. The most commonly used anesthesia was subdural (68.37\%). Complications encountered during the surgical procedure were bladder lesions $(8.54 \%)$ and hemorrhage (1.28\%), with conversion to abdominal surgery being necessary in one case (1.28\%) because of bleeding. General intraoperative characteristics for the study population are summarized in Table 2.

\section{Postoperative characteristics}

Hospitalization time ranged from 24 hours to 48 hours (82.05\% and $17.94 \%$, respectively). The most common complications were vaginal cupola granuloma in $32.47 \%$, urinary tract infection in $12.82 \%$, and vaginal cupola hematoma in $2.56 \%$ of cases. Chi-square testing showed a statistically significant relationship between surgery time and uterine volume $\left(\chi^{2}=17.367 ; P=0.002\right)$, but not for surgery time and associated surgery $\left(\chi^{2}=0.640 ; P=0.726\right)$, or surgery time and previous related surgery $\left(\chi^{2}=3.063 ; P=0.216\right)$. General postoperative characteristics from the study population and comparisons between surgery time and uterine volume, surgery time and associated surgery, surgery time and need for additional surgery, and surgery time and prior surgery are summarized in Tables 3-7. All women in this study were already patients attending the outpatient clinics of the operating surgeons, so there were no dropouts or patients lost to follow-up.

\section{Discussion}

Hysterectomy is the most common surgical procedure performed for uterine disease, with up to $20 \%$ women undergoing the procedure by the age of 60 years in the 20th century. ${ }^{16}$ Despite the introduction of minimally invasive approaches to treat various benign uterine problems, and the long time period for which the vaginal route has been used to perform hysterectomy for benign uterine disease, hysterectomy is still performed abdominally in most cases, and the vaginal approach is used in only $20 \%-25 \%$ of women who undergo the procedure in the US regardless of the indication. ${ }^{4,8,10,17,18}$

It has been shown that the vaginal route is more advantageous than any other approach to hysterectomy for a number of reasons, including a shorter recovery time, less pain in the postoperative period, a rapid return to former activity levels, and absence of visible scarring. ${ }^{9,10,19}$

The aim of our study was to evaluate preoperative, intraoperative, and postoperative characteristics of women undergoing removal of the uterus. Our results are similar to those of other studies in the literature, which have reported a patient age range of 41-50 years, ${ }^{9,10,20-25}$ myoma as the main indication, spinal anesthesia as the most commonly used anesthetic procedure, ${ }^{22-24}$ volume uterine reduction often being performed, a surgery time of about 75 minutes, and oophorectomy being a frequently associated procedure. ${ }^{10,20,22,26}$

In a similar study of 190 women reported by Prota, ${ }^{11}$ the mean patient age was 44.6 years, $91 \%$ of women had had at least one prior pregnancy, and $72.1 \%$ had undergone a cesarean section. The most common indication for surgery was uterine myoma causing abnormal vaginal bleeding. Uterine volume reduction was performed in $50 \%$ of cases, and surgery additional to the main procedure was performed in $22.6 \%$. Spinal anesthesia was frequently performed, and the duration of surgery was up to 75 minutes in $58.9 \%$ of cases. Postoperative complications were observed in 3.7\%, with bladder lesions being the most common, and patient recovery time was less than 48 (mean 31.5 ) hours in $87.4 \%$ of cases.

Harmanli et al conducted a comparative study of the vaginal and abdominal routes for hysterectomy, and reported results similar to ours for mean patient age and parity, frequency of adnexal removal, and indications for hysterectomy (mainly uterine fibroids, menometrorrhagia, pelvic pain). ${ }^{3}$

Table 4 Descriptive analysis for quantitative variables $(n=117)$

\begin{tabular}{lclll}
\hline Variable & Mean/SD & Median & Minimum & Maximum \\
\hline Age (y) & $45.21 \pm 5.57$ & 46 & 33 & 59 \\
Parity & $2.4 \pm 0.87$ & 2 & 1 & 6 \\
Uterine volume (c $\left.{ }^{3}\right)$ & $327.33 \pm 216.01$ & 240 & 90 & 90 \\
Surgery time (minutes) & $43.15 \pm 18.06$ & 38 & 20 & 90 \\
Hospitalization time (hours) & $31.39 \pm 11.08$ & 24 & 24 & 48 \\
\hline
\end{tabular}


Table 5 Correlation between surgery time and uterine volume $(n=117)$

\begin{tabular}{llll}
\hline $\begin{array}{l}\text { Surgery time } \\
\text { (minutes) }\end{array}$ & \multicolumn{3}{l}{ Uterine volume (cc) } \\
\cline { 2 - 4 } & Until $\mathbf{3 0 0}$ & $\mathbf{3 0 I}$ to $\mathbf{6 0 0}$ & $\mathbf{6 0 1}$ to $\mathbf{9 0 0}$ \\
\hline Until 30 & 53 & 12 & 4 \\
31 to 60 & 21 & 8 & 9 \\
$>60$ & 2 & 5 & 3 \\
\hline
\end{tabular}

Notes: Chi-square $=17.367 ; \quad P=0.002$.

An apparent limitation of our study is the lack of a control group against which to compare our results; however, followup was continued for at least 12 months, which is arguably adequate to assess the outcome of vaginal hysterectomy.

Some authors have cited a number of factors that may influence the route of hysterectomy for benign causes, including the size and shape of the vagina and uterus, accessibility to the uterus, extent of extrauterine disease, need for concurrent procedures, surgeon training and experience, available hospital technology and support, emergency or scheduled cases, and the preference of the informed patient. ${ }^{5} \mathrm{~A}$ narrow pubic arch (less than 90 degrees), an undescended immobile uterus, nulliparity, and prior cesarean delivery have also been proposed by some authors as contraindications for vaginal hysterectomy, ${ }^{6}$ but were not confirmed in our study.

In our series, vaginal hysterectomies were performed in many women who had never given birth vaginally and in some with a uterine volume larger than $300 \mathrm{~mL}$ but with adequate vaginal caliber to allow successful completion of surgery, with no complications or additional surgical time needed. Doucette et al have reported that if the vagina can allow access to divide the uterosacral and cardinal ligaments, uterine mobility is usually increased enough to allow vaginal hysterectomy, even in cases where there is minimal uterine descent, and when the uterus is enlarged, vaginal hysterectomy often can be accomplished safely by using uterine size reduction techniques, such as wedge morcellation, uterine bisection, and intramyometrial coring. ${ }^{12}$

When performing routinely bilateral salpingooophorectomy where possible we make it hidrosalpinx and ovarian cancer prevention, and so in this work we

Table 6 Correlation between surgery time with- or nocomplementary surgery achievement $(n=117)$

\begin{tabular}{lll}
\hline $\begin{array}{l}\text { Surgery time } \\
\text { (minutes) }\end{array}$ & $\begin{array}{l}\text { With associate } \\
\text { surgery }\end{array}$ & $\begin{array}{l}\text { No associate } \\
\text { surgery }\end{array}$ \\
\hline Until 30 & 16 & 68 \\
31 to 60 & 4 & 22 \\
$>60$ & 2 & 5 \\
\hline
\end{tabular}

Notes: Chi-square $=0.640 ; P=0.726$.
Table 7 Correlation between surgery time in presence, or not, of previous surgery $(n=117)$

\begin{tabular}{lll}
\hline $\begin{array}{l}\text { Surgery time } \\
\text { (minutes) }\end{array}$ & $\begin{array}{l}\text { Prior } \\
\text { surgery }\end{array}$ & $\begin{array}{l}\text { No prior } \\
\text { surgery }\end{array}$ \\
\hline Until 30 & 44 & 39 \\
31 to 60 & 17 & 7 \\
$>60$ & 7 & 3 \\
\hline
\end{tabular}

Notes: Chi-square $=3.063 ; P=0.216$.

reached levels of $81.19 \%$ for salpingectomy and $26.49 \%$ for oophorectomy associate to vaginal hysterectomy. Reports in the literature indicate that most ovaries are visible and readily accessible during vaginal surgery, and it is generally safe to perform bilateral salpingo-oophorectomy at the time of vaginal hysterectomy. ${ }^{26,27}$ We believe that the elective decision to perform routine bilateral salpingo-oophorectomy is not a contraindication to performing vaginal hysterectomy. The most common recovery time was 24 hours, which we consider advantageous compared with abdominal hysterectomy, after which the recovery time is usually 48 hours. The most common postoperative complication was vaginal cupola granuloma (32.47\%) which we considered to be irrelevant in terms of both frequency and severity. The other postoperative complications were vaginal cupola hematoma in $2.56 \%$ of cases and urinary infection in $12.82 \%$.

In a randomized trial, Benassi et al compared the outcomes of the two methods of hysterectomy for a uterine weight of $200 \mathrm{~g}$ or more. They found that the complication rates were not significantly different, except for postoperative fever, which occurred more often after an abdominal procedure. ${ }^{9}$

Our results show a shorter recovery time, what is economically appealing, and reiterates the results of other studies showing that vaginal hysterectomy is a safe surgical approach in women with any indication for hysterectomy, and with a low complication rate. It is likely that many patients would choose the vaginal route if it is presented as an option that eliminates abdominal wound complications and leaves no visible scars. ${ }^{3}$

\section{Conclusion}

Vaginal hysterectomy is a safety surgical route for hysterectomy, with favorable performance and a low complication rate.

\section{Disclosure}

The authors report no conflicts of interest in this work.

\section{References}

1. Nieboer TE, Johnson N, Lethaby A, et al. Surgical approach to hysterectomy for benign gynaecological disease. Cochrane Database Syst Rev. 2009;3:CD003677. 
2. Farquhar CM, Steiner CA. Hysterectomy rates in the United States 1990-1997. Obstet Gynecol. 2002;99:229-234.

3. Harmanli OH, Gentzler CK, Byun S, Dandolu V, Grody MHT. A comparison of abdominal and vaginal hysterectomy for the large uterus. Int J Gynaecol Obstet. 2004;87:19-23.

4. American College of Obstetricians and Gynecologists. Precis IV: An Update in Obstetrics and Gynecology. Washington, DC: 1989. [CD-ROM].

5. Wu JM, Wechter ME, Geller EJ, Nguyen TV, Visco AG. Hysterectomy rates in the United States, 2003. Obstet Gynecol. 2007;110: 1091-1095.

6. [No authors listed]. ACOG Committee Opinion No 444. Choosing the route of hysterectomy for benign disease. Obstet Gynecol. 2009; $114: 1156-1158$.

7. Tohic AL, Dhainaut C, Yazbeck C, Hallais C, Levin I, Madelenat P. Hysterectomy for benign uterine pathology among women without previous vaginal delivery. Obstet Gynecol. 2008;111:829-837.

8. Deval B, Rafii A, Soriano D, Samain E, Levardon M, Darai E. Morbidity of vaginal hysterectomy for benign tumors as a function of uterine weight. J Reprod Med. 2003;48:435-440.

9. Benassi L, Rossi T, Kaihura CT, et al. Abdominal or vaginal hysterectomy for enlarged uteri: a randomized clinical trial. Am J Obstet Gynecol. 2002;187:1561-1565.

10. Hwang JL, Seow KM, Tsai YL, Huang LW, Hsieh BC, Lee C. Comparative study of vaginal, laparoscopically assisted vaginal and abdominal hysterectomies for uterine myoma larger than $6 \mathrm{~cm}$ in diameter or uterus weighing at least $450 \mathrm{~g}$ : a prospective randomized study. Acta Obstet Gynecol Scand. 2002;81:1132-1138.

11. Prota FE. Pre, intra and postoperative parameters of women undergoing vaginal hysterectomy in the absence of uterine prolapse Thesis $(\mathrm{PhD})$ [Parâmetros pré, intra e pós-operatórios de mulheres submetidas à histerectomia vaginal na ausência de prolapso uterino Tese (Doutorado)] Universidade Estadual de Campinas. 2006.

12. Doucette RC, Sharp HT, Alder SC. Challenging generally accepted contraindications to vaginal hysterectomy. Am J Obstet Gynecol. 2001;184:1386-1389.

13. International Continence Society, Committee on Standardisation of Terminology. The standardization of terminology of lower urinary tract function. In: Ostergard DR, Bent AE, editors. Urogynecology and Urodynamics: Theory and Practice. 3rd ed. Baltimore, MD: Williams and Wilkins; 1991.

14. Bump RC, Mattiasson A, Bo K. The standardization of terminology of female pelvic organ prolapse and pelvic floor dysfunction. Am J Obstet Gynecol. 1996;175:10-17.
15. Persu C, Chapple CR, Cauni V, Gutue S, Geavlete P. Pelvic Organ Prolapse Quantification System (POP-Q) - a new era in pelvic prolapse staging. J Med Life. 2011;4:75-81.

16. Royal College of Obstetricians and Gynaecologists The management of menorrhagia in secondary care. London: RCOG Press, 1999. (Evidencebased clinical guideline No 5).

17. Magos A, Bournas NO, Sinha R, Richardson RE, O'Connor H. Vaginal hysterectomy for the large uterus. Br J Obstet Gynecol. 1996;103:246-251.

18. Dicker RC, Greenspan JR, Strauss LT, et al. Complications of abdominal and vaginal hysterectomy among women of reproductive age in the United States: the Collaborative Review of Sterilization. Am J Obstet Gynecol. 1982;144:841-848.

19. Hoffman MS, DeCesare S, Kalter C. Abdominal hysterectomy versus transvaginal morcellation for the removal of enlarged uteri. Am J Obstet Gynecol. 1994;171:309-313.

20. Figueiredo Netto O, Figueiredo EG, Figueiredo PG, Pelosi MA, Pelosi MA IIIRD. Vaginal removal of the benign non-prolapsed uterus: experience with 300 consecutive operations. Obstet Gynecol. 1999;94:348-351.

21. Ribeiro SC, Ribeiro RM, Santos NC, Pinotti JA. A randomized study of total abdominal, vaginal and laparoscopic hysterectomy. Int J Gynaecol Obstet. 2003;83:37-43.

22. Miskry T, Magos A. Randomized, prospective, double-blind comparison of abdominal and vaginal hysterectomy in women without uterovaginal prolapse. Acta Obstet Gynecol Scand. 2003;82:351-358.

23. Darai E, Soriano D, Kimata P, Laplace C, Lecuru F. Vaginal hysterectomy for enlarged uteri, with or without laparoscopic assistance: randomized study. Obstet Gynecol. 2001;97(5 Pt 1):712-716.

24. Ottosen C, Lingman G, Ottosen L. Three methods for hysterectomy: a randomised, prospective study of short term outcome. Br J Obstet Gynaecol. 2000;107:1380-1385.

25. Soriano D, Goldstein A, Lecuru F, Darai E. Recovery from vaginal hysterectomy compared with laparoscopy-assisted hysterectomy: a prospective, randomized, multicenter study. Acta Obstet Gynecol Scand. 2001;80:337-341.

26. Sheth SS. The scope of vaginal hysterectomy. Eur J Obstet Gynecol Reprod Biol. 2004;115:224-230.

27. Kovac SR. Hysterectomy outcomes in patients with similar indications. Obstet Gynecol. 2000;95:787-793.
International Journal of Women's Health

\section{Publish your work in this journal}

The International Journal of Women's Health is an international, peerreviewed open-access journal publishing original research, reports, reviews and commentaries on all aspects of women's healthcare including gynecology, obstetrics, and breast cancer. Subject areas include: Chronic conditions (migraine headaches, arthritis, osteoporosis);

\section{Dovepress}

Endocrine and autoimmune syndromes; Sexual and reproductive health; Psychological and psychosocial conditions. The manuscript management system is completely online and includes a very quick and fair peer-review system. Visit http://www.dovepress.com/ testimonials.php to read real quotes from published authors. 